\title{
O uso de ferramentas digitais de comunicação como recurso para o planejamento colaborativo e interdisciplinar docente
}

\author{
Cibelle Cristina Barros de Almeida, Ádila de Lima Ferreira, Bárbara Fernandes da \\ Silva de Souza, Bruna Patrícia da Silva Braga Baracho, Isabel Dillmann Nunes, \\ Lucineide Cruz Araújo, Maria Cristina Leandro Paiva \\ e Maria da Conceição Lima Vieira
}

\begin{abstract}
Instituto Metrópole Digital - Universidade Federal do Rio Grande do Norte (UFRN) Natal/RN

Master in Innovation in Educational Technologies

adilaferreiral4@gmail.com, barbara@imd.ufrn.br, brunapbraga@gmail.com, cibellephabullomellinamiguel@gmail.com, neidinha.araujo@hotmail.com, lisarbcei@gmail.com
\end{abstract}

\begin{abstract}
This article presents the results of a descriptive research carried out in a public institution of the final years of elementary and high school, located in the city of Natal. The objective is to investigate how the planning of the teachers in the school scope happens and if they use digital tools of communication that promote the collaboration. The data obtained through the application of an online questionnaire showed that the time factor interferes in the effectiveness of the collaborative planning, and that even using these tools on a daily basis, they are not used by most of the participants in the planning, but exist in every group interested in knowing their possibilities for the pedagogical work.
\end{abstract}

Resumo. Este artigo apresenta o resultado de uma pesquisa descritiva realizada em uma instituição pública dos anos finais do ensino fundamental e ensino médio, localizada na cidade de Natal. $O$ objetivo é investigar como acontece o planejamento dos professores no âmbito escolar e se usam ferramentas digitais de comunicação que promovem a colaboração. Os dados obtidos através da aplicação de um questionário on-line, demonstraram que o fator tempo interfere na efetivação do planejamento colaborativo, e que mesmo fazendo uso cotidianamente destas ferramentas, elas não são utilizadas pela maior parte dos participantes no planejamento, mas que existe em todo grupo interesse em conhecer suas possibilidades para o trabalho pedagógico.

\section{INTRODUÇÃO}


VII Congresso Brasileiro de Informática na Educação (CBIE 2018)

Anais do XXIV Workshop de Informática na Escola (WIE 2018)

A sociedade atual encontra-se essencialmente imersa na era digital, caracterizada pelo uso das tecnologias digitais da informação e comunicação (TDICs), ocasionando profundas modificações na forma de diálogo entre as pessoas e no acesso à informação e ao conhecimento. Esse cenário revela um novo panorama para educação, pois como afirmam Almeida e Valente (2011 p. 06) "as tecnologias fazem parte das nossas vidas, influenciam o processo de estruturação do nosso pensamento e, em especial, o modo de ser, agir e pensar das gerações que hoje frequentam nossas salas de aula".

Nesse sentido, cada dia mais se torna necessário aproveitar as possibilidades que as tecnologias digitais podem oferecer para o trabalho pedagógico das instituições escolares. Elas podem trazer um caminho possível para a articulação e engajamento do trabalho docente a partir dos seus recursos midiáticos e de comunicação, principalmente quando se trata do planejamento colaborativo docente, que é o foco deste estudo.

A proposta de planejamento dos professores da escola pública do Estado do Rio Grande do Norte, nem sempre corrobora para a efetivação de um trabalho colaborativo. Os próprios documentos norteadores da jornada de trabalho não especifica como este planejamento deve ser desenvolvido no período das dez (10) horas destinadas para este fim. O que fica em evidência são apenas os tipos de atividades que precisam ser realizadas. Leia-se os artigos referentes a carga horária de trabalho destinada ao professor de acordo com a Portaria $n^{\circ} 114 / 2018-S E E C / G S$, lançada no diário oficial do estado:

\footnotetext{
$\S 2^{\circ}$. A jornada de trabalho do Professor, no exercício da docência nas Escolas da Rede Estadual, compreende 20 (vinte) horas semanais em sala de aula e $10(\mathrm{dez})$ horas para atividades como preparação e avaliação do trabalho didático, colaboração com a administração da Escola, reuniões pedagógicas, articulação com a comunidade e qualificação profissional.

$\S 3^{\circ}$ No mínimo, 5(cinco) horas deverão ser destinadas a trabalho coletivo, com a presença do Professor na Unidade Escolar.
}

Esta portaria também afirma que cinco (5) horas são destinadas para o trabalho coletivo presencial na escola, porém uma das dificuldades mais comuns é a falta de tempo para que os professores de diferentes áreas de conhecimento possam planejar coletivamente, o que vem provocando fragmentação e isolamento das disciplinas, fragilizando assim o currículo. Essa problemática chama atenção para a importância de aproveitar as possibilidades das ferramentas digitais de comunicação para facilitar o planejamento colaborativo docente, pois podem romper as barreiras que dificultam o diálogo presencial, substituído pelo virtual que também pode acontecer em tempo real dependendo da disponibilidade dos pares, independente da distância que os separam.

Partindo desse contexto, este artigo apresenta o resultado de uma pesquisa descritiva realizada em uma escola pública estadual dos anos finais do ensino fundamental e ensino médio, localizada na cidade de Natal. O objetivo é investigar como acontece o planejamento dos professores no ambiente escolar e se usam ferramentas digitais de comunicação que promovem a colaboração. Para o alcance dessa finalidade, foi realizado um estudo bibliográfico para aprofundamento do assunto, sendo discutido o planejamento docente, os ambientes colaborativos de aprendizagem, modelo $3 \mathrm{C}$ de Colaboração e interdisciplinaridade e depois a aplicação de um questionário online para a análise do objeto de estudo. 
VII Congresso Brasileiro de Informática na Educação (CBIE 2018)

Anais do XXIV Workshop de Informática na Escola (WIE 2018)

O presente trabalho está organizado da seguinte maneira: na seção 2 apresenta-se o referencial teórico sobre "Planejamento docente em uma perspectiva colaborativa e interdisciplinar", na seção 3 são relatados os "Procedimentos Metodológicos" utilizados para a realização do trabalho, na seção 4 apresentam-se as análises dos resultados acerca do tema pesquisado através das respostas obtidas pelos participantes da pesquisa que responderam ao formulário eletrônico disponibilizado e, por fim, apresentam-se as considerações finais.

\section{PLANEJAMENTO DOCENTE EM UMA PERSPECTIVA COLABORATIVA E INTERDISCIPLINAR}

Planejar é algo presente na vida das pessoas, pois a todo o momento se toma decisões, que algumas vezes são definidas a partir de improvisações, e em outras são necessárias ações previamente organizadas. Reportando-se para a educação, o planejamento também é entendido como um processo de sistematização e organização das ações do professor. É um instrumento da racionalização do trabalho pedagógico que articula a atividade escolar com os conteúdos do contexto social (LIBÂNEO, 2013).

Diante das mudanças atuais na forma de se relacionar com o conhecimento, ficou mais evidente a necessidade da integralização do currículo e do trabalho docente interligado pelas diversas áreas. O que urge é pensar o planejamento pedagógico de forma colaborativa, principalmente quando se trata de direcionar o processo de ensino-aprendizagem, que não pode mais ser visto e concebido como uma tarefa isolada.

Daí a importância de buscar meios que possam favorecer a construção de um currículo colaborativo. Nesse sentido, é fundamental tornar os profissionais da educação conhecedores das possibilidades de se trabalhar conjuntamente os ambientes colaborativos de aprendizagem, apontando as diversas versões, modelos e teorias que os embasam e os tornam acessíveis ao trabalho pedagógico disponíveis na internet como o google através do Google Docs, Google Forms e Google Classroom, além de outras possibilidades oferecidas por empresas que oferecem este tipo de ambiente como Kahoot, Canva, etc.

A usabilidade de ferramentas digitais colaborativas são capazes de estimular a cooperação entre os professores, otimização de tempo, aproximação de diferentes conceitos para a resolução de problemas entre diferentes áreas de conhecimento, garantindo a construção de um espaço democrático para o trabalho pedagógico com a inserção da cultura digital. Além disso, conforme Sales e Cruz (2012 p.1895.) "essas ferramentas abrem um leque de possibilidades para o desenvolvimento do processo ensino-aprendizagem devido a facilidade de uso e a velocidade na divulgação das informações".

O trabalho colaborativo requer algumas metodologias. Aqui nos debruçamos no Modelo 3C de Colaboração os quais possuem três características específicas: a Comunicação, onde há compartilhamento de informações em que se pode emitir opiniões e ouvir a do outro; Cooperação, por meio da qual existem trocas e ações ativas e uma Coordenação ou conjunto de regras que norteiam o trabalho a ser realizado, e simbolizam um acordo entre os participantes das regras para chegarem a um determinado objetivo. Segundo Pimentel e Fuks (2012, p. 25) "No Modelo 3C, [...], a separação em dimensões foca nos aspectos relevantes para a análise da colaboração, entretanto, os Cs se inter-relacionam para que a colaboração ocorra". 
VII Congresso Brasileiro de Informática na Educação (CBIE 2018)

Anais do XXIV Workshop de Informática na Escola (WIE 2018)

Assim sendo, compreende-se que para o planejamento acontecer de forma eficaz e colaborativa, é necessário o envolvimento de todos - professores, coordenadores - de modo que eles estejam abertos ao diálogo e compartilhem dos seus saberes. Diante disto o Modelo $3 \mathrm{C}$ se coloca como uma possibilidade de concretização de trabalho em grupo mais eficiente.

\begin{abstract}
No trabalho em grupo, a comunicação é voltada para a ação. Enquanto se comunicam, as pessoas negociam e tomam decisões. Enquanto se coordenam, os membros do grupo lidam com conflitos e organizam as atividades para evitar o desperdício de comunicação e dos esforços de cooperação. A necessidade de renegociar e tomar decisões sobre situações imprevistas que ocorrem durante a cooperação demanda comunicação que, por sua vez, demanda coordenação para eorganizar as tarefas. Por meio de informações de percepção, o indivíduo obtém feedback de suas ações e feedthrough das ações de seus colegas. (PIMENTEL; FUKS, 2012, p. 25)
\end{abstract}

No caso do planejamento colaborativo, o trabalho do coordenador pedagógico é essencial para que todos os projetos que venham a ser desenvolvidos estejam interligados por uma visão maior de currículo, sendo ele o articulador entre os professores e as diversas áreas de ensino.

A concretização e articulação desse trabalho conhecido como interdisciplinaridade pedagógica, busca promover o diálogo entre as disciplinas e oferece um caminho para superar a fragmentação do saber, permitindo que haja ganho na qualidade do ensino oferecido aos alunos. Neste ponto, reforça-se a expressão diálogo entre as disciplinas, pois acredita-se que cada disciplina tem sua função e seu papel a cumprir, principalmente no que diz respeito às descobertas e aos avanços científicos.

Segundo Fazenda (2002 p.64) a atitude interdisciplinar não está na junção de conteúdos ou métodos; nem na junção de disciplina, muito menos na criação de novos conteúdos produto dessas organizações; ela está contida nas pessoas que pensam o projeto educativo.

Mesmo sendo um grande desafio para as instituições educativas, as práticas interdisciplinares podem contribuir para a qualidade da educação, provocando maior desafio aos estudantes nas trocas de leitura, diálogo, pesquisa, reflexão. Logo, entende-se que isso também é possível de ocorrer através de recursos digitais colaborativos, desde que todos os envolvidos participem efetivamente e trabalhem no sentido da Comunicação, Cooperação e Coordenação, conforme o que propõe o Modelo 3C de colaboração.

\title{
3 METODOLOGIA
}

Esta pesquisa é proveniente das inquietações das pesquisadoras a respeito do planejamento docente, como estava ocorrendo em seus ambientes de trabalho educacional. Desta forma sentiu-se a necessidade de investigar como acontece o planejamento dos professores no âmbito escolar e se fazem uso de ferramentas digitais de comunicação capazes de promover a colaboração.

Para isso foi realizada, quanto aos objetivos, uma pesquisa descritiva que tem como função observar fatos e coletar dados sobre um ambiente, onde se queira entender determinadas problemáticas. Neste caso, o ambiente escolhido, foi uma Escola Estadual, que 
VII Congresso Brasileiro de Informática na Educação (CBIE 2018)

Anais do XXIV Workshop de Informática na Escola (WIE 2018)

trabalha com os anos finais do ensino fundamental, assim como ensino médio, localizada no município de Natal/RN. De acordo com Ciribelli (2003, p. 54) "Na pesquisa descritiva, os fatos são observados, registrados, analisados, classificados e interpretados sem que o pesquisador interfira neles."

Também foi aprofundado o conhecimento sobre o assunto a partir de estudo bibliográfico, com foco em artigos científicos e livros que tratam sobre planejamento docente, ambientes colaborativos de aprendizagem, modelo 3C de colaboração e interdisciplinaridade. Para Gil (2009) a principal vantagem da pesquisa bibliográfica reside no fato de permitir ao investigador a cobertura de uma gama de fenômenos muito mais ampla do que aquela que poderia pesquisar diretamente.

Em relação a coleta dos dados, as pesquisadoras escolheram o questionário on-line como instrumento a ser utilizado. "Em geral, a Pesquisa Descritiva usa como técnica de coleta de dados, a observação, os questionários, as entrevistas e os levantamentos" (CIRIBELLI, 2003, p. 54). Essa escolha partiu de uma discussão inicial para em seguida a elaboração das perguntas no Google Docs de forma colaborativa e por fim a sistematização das informações no formulário do Google Forms.

Um destes serviços oferecidos é o Google Docs, uma espécie de suíte de aplicativos online, bastante semelhante ao Microsoft Office e ao OpenOffice.org/BrOffice.org. O serviço da Google possui editor de textos, editor de planilhas eletrônicas, editor de apresentação de slides e ainda ferramenta para criação de formulários (enquetes). (CIRÍACO, 2008)

O questionário eletrônico foi composto por 16 perguntas, que versaram sobre o perfil dos participantes e suas concepções em relação ao planejamento. É válido destacar que o link gerado pelo formulário ${ }^{1}$ foi disponibilizado no grupo do Whatsapp dos professores da escola, pensando na facilidade do acesso e participação na pesquisa.

Os dados foram analisados e compilados de forma quantitativa, utilizando os recursos da própria ferramenta, Google Forms, que gera gráficos e planilhas de forma automática, sendo possível verificar a ótica dos entrevistados sobre como realizam os seus planejamentos, quais as principais dificuldades enfrentadas na sua realização, bem como as possibilidades do uso de ferramentas digitais para que haja colaboração e interdisciplinaridade no ato de planejar.

\subsection{Universo da Amostra}

A Escola participante deste estudo está localizada em um bairro de classe média baixa e atende comunidades pobres circunvizinhas. Possui cerca de 640 alunos, funciona nos três turnos e oferece turmas dos anos finais do ensino fundamental e ensino médio.

Considerando o perfil da amostra, responderam ao questionário vinte e nove (29) professores, três (3) coordenadores pedagógicos e um (1) diretor. Entre os professores, muitos atuam em mais de um segmento educacional, como demonstra o gráfico 1.

${ }^{1}<\underline{\text { https: } / / g o o . g l / f o r m s / t F B i P k n j V P 3 F N H O f l>~}$ 
VII Congresso Brasileiro de Informática na Educação (CBIE 2018)

Anais do XXIV Workshop de Informática na Escola (WIE 2018)

7. Em que nível de ensino você atua?

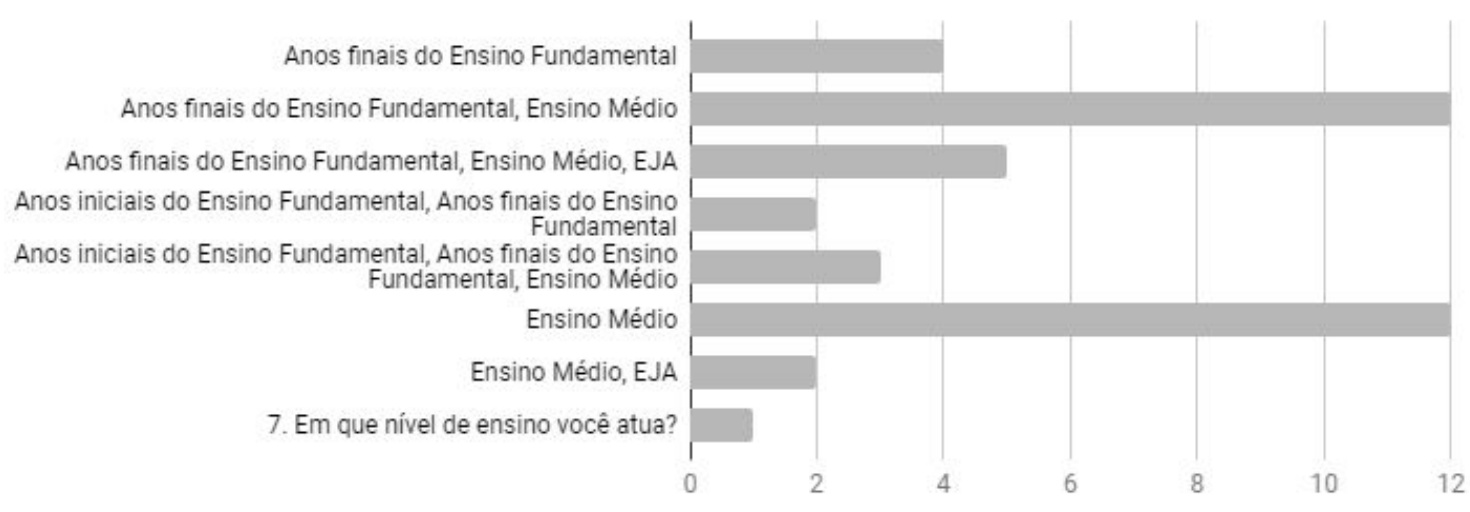

Gráfico 1: Questão 7 do instrumento de pesquisa.

Percebeu-se também que os participantes estão mesclados em diversas faixa etárias, tendo em sua maioria, ou seja, 45,5\% entre 31 e 40 anos; 51,5\% são do gênero masculino; $39,4 \%$ possuem especialização e $27,3 \%$ possui apenas a graduação como formação; e quanto ao tempo de atuação $69,7 \%$ possuem mais de sete (7) anos de sala de aula.

\section{ANÁLISE DOS RESULTADOS}

O planejamento na escola investigada, ocorre em dias pré estabelecidos, porém nem todos os entrevistados concordaram com essa afirmativa, e 39,4\% afirmaram não ter dias fixos no calendário escolar para o planejamento.

Foi perguntado se conseguiam realizar o planejamento no ambiente escolar e $55,5 \%$ afirmaram não conseguir realizar esse planejamento. Essa questão abriu uma nova sessão em que foi questionado o motivo para a não realização desse planejamento, 33,3\% alegaram que a excessiva jornada de trabalho, pois eles têm vínculos em outras instituições, esse fato impede o planejamento entre os pares; o mesmo percentual afirma que os horários fracionados de planejamento, mesclados com aula, dificulta esse momento. A falta de estrutura física da escola, sem um espaço ou equipamentos propícios para planejar, tais como impressora e internet, a dificuldade de articulação entre a equipe pedagógica, foram apontados como impeditivos para a desarticulação do planejamento no espaço escolar.

No gráfico 02 podemos observar o resultado obtido quando indagamos os entrevistados sobre o planejamento coletivo por área de ensino. 
VII Congresso Brasileiro de Informática na Educação (CBIE 2018)

Anais do XXIV Workshop de Informática na Escola (WIE 2018)

11. Você consegue planejar com outros professores da mesma área de conhecimento?

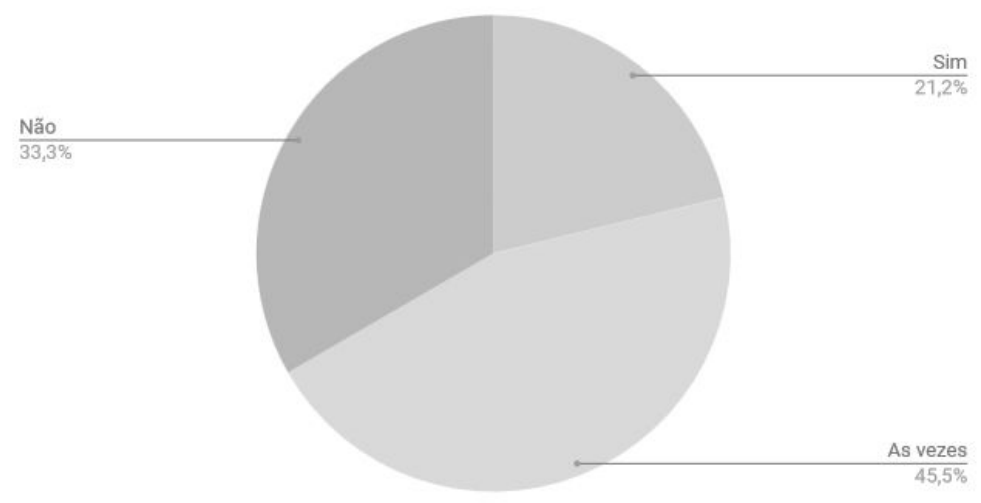

Gráfico 2: Questão 11 do instrumento de pesquisa.

Apenas 21,2\% apontam conseguir realizar o planejamento com outros professores da mesma área de conhecimento, no entanto percebe-se que algumas ações escolares desenvolvem o planejamento interdisciplinar quando $45,5 \%$ dos respondentes dizem às vezes conseguem realizá-los, 33,3\% alegam não conseguir planejar por área de ensino, principalmente, por que seus horários de planejamento não condizem com o dos colegas de trabalho.

Em relação ao envolvimento dos coordenadores pedagógicos na integração entre os professores no planejamento, $60 \%$ dos participantes informam que esses coordenadores articulam o trabalho de forma que as disciplinas dialogam umas com outras e possa assim haver um trabalho interdisciplinar.

Quanto ao planejamento realizado em ambientes colaborativos via internet ou com o uso de ferramentas tecnológicas que facilite esse planejamento, obtive-se os seguintes resultados:

13. Você já participou de planejamento colaborativo, utilizando a internet?

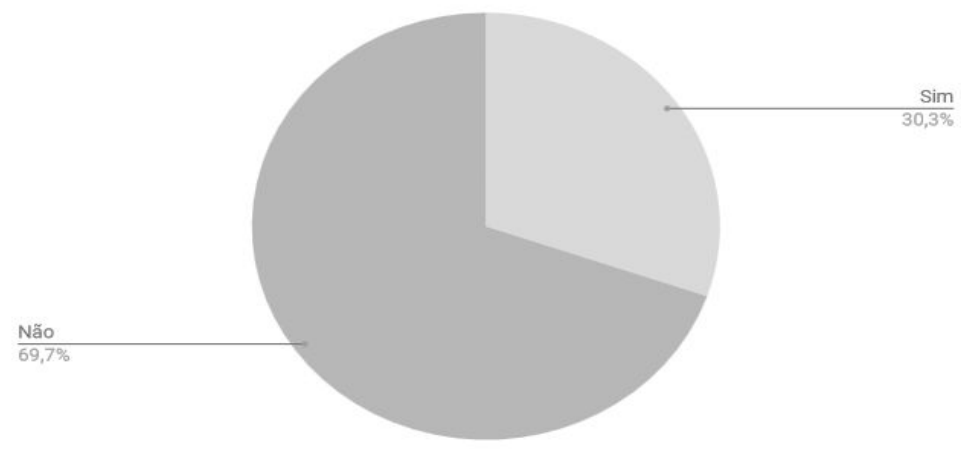

Gráfico 3: Questão 13 do instrumento de pesquisa. 
VII Congresso Brasileiro de Informática na Educação (CBIE 2018)

Anais do XXIV Workshop de Informática na Escola (WIE 2018)

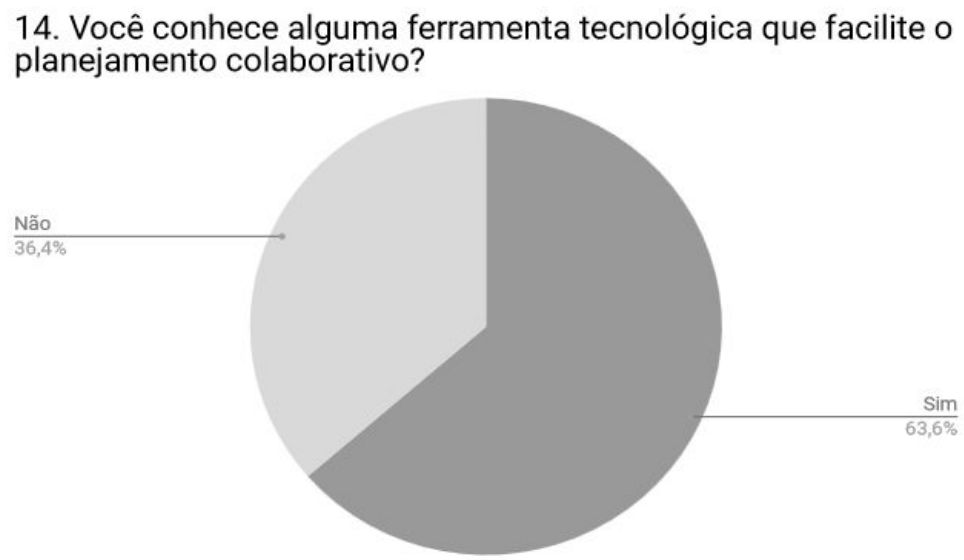

Gráfico 4: Questão 14 do instrumento de pesquisa.

Verificou-se que nos gráficos 2 e 3 os valores são inversamente proporcionais, visto que no gráfico 2, 69,7\% dos entrevistados afirmaram não ter participado do planejamento colaborativo utilizando a internet, enquanto que no gráfico 3, 63,6\% informaram que já conheciam as ferramentas tecnológicas que facilitam o planejamento colaborativo.

Todos os participantes acreditam ser importante a promoção de formação voltada para o conhecimento de ambientes e sistemas colaborativos que facilitam o planejamento entre os pares. Assim como, mais de 90\% dos entrevistados utilizam o Facebook ou Whatsapp para se comunicarem, o que indica certa familiaridade com uso de internet no seu dia a dia. Quase $50 \%$ informou que utilizam ou já utilizaram o Google Docs.

\section{CONCLUSÕES}

$\mathrm{Na}$ atualidade, com os diversos aparatos tecnológicos disponíveis, é necessário rever o formato de planejamento vigente e buscar nos meios digitais, instrumentos que possibilitem outras trocas de integração como tentativa de fortalecer o diálogo e o engajamento das diversas áreas em um único arquivo. Desenvolver um planejamento colaborativo entre professores de diversas disciplinas pode ressignificar a construção curricular na perspectiva de preparar o planejamento escolar com troca de ideias e construção coletiva de planos e projetos para transpor para sala de aula conceitos em linguagem articulada que promovam a aprendizagem de um modo global, quebrando assim com a ideia do ensino compartimentado.

A partir desta pesquisa foi possível perceber que pode ser viável, trabalhar o planejamento de forma interdisciplinar com o uso dos recursos digitais colaborativos, uma vez que esse exercício possibilita a construção e ampliação do saber entre as diferentes áreas do conhecimento, proporcionando uma dinâmica efetiva de trocas interpessoais para a estruturação de novas práticas de trabalho. Porém, o planejamento colaborativo on line aponta para a necessidade de adequação e controle de agenda de tempo dos envolvidos, pois devido a falta de internet e equipamentos em bom estado de funcionamento nas escolas públicas, um trabalho dessa natureza, tende a ser desenvolvido fora das escolas, portanto, talvez não se 
VII Congresso Brasileiro de Informática na Educação (CBIE 2018)

Anais do XXIV Workshop de Informática na Escola (WIE 2018)

pode contar com aquele "horário quebrado" que o professor dispõe na escola, para a efetivação dessa proposta.

Com base na análise dos resultados, pode-se concluir que a logística de tempo dedicado ao planejamento adotado pelo Governo do Estado do Rio Grande do Norte, pode estar prejudicando o trabalho coletivo no momento em que dificulta o encontro face to face dos docentes na escola para o desenvolvimento de planejamento colaborativo e interdisciplinar.

Conclui-se também que a maioria dos participantes usam cotidianamente as ferramentas digitais de comunicação, mas não como recurso para facilitar o planejamento. Essa necessidade despertou em todo grupo da amostra o interesse em conhecer as possibilidade de uso pedagógico dessas ferramentas na perspectiva da colaboração.

Como desdobramento da pesquisa, pretende-se ao longo do segundo semestre de 2018 oferecer, na escola pesquisada, uma oficina formativa para os professores sobre o uso da ferramenta digital Google Docs, tendo em vista apresentar as possibilidades para o planejamento docente compartilhado, por permitir a comunicação e escrita colaborativa. A partir da oficina será realizada uma nova investigação acerca do seu impacto no planejamento escolar, o que possibilitará implementar e divulgar alternativas quanto a otimização do tempo pedagógico do professor.

\section{REFERÊNCIAS}

ALMEIDA, M.; VALENTE, J. "Tecnologias e currículo: trajetórias convergentes ou divergentes". São Paulo: Paulus, 2011.

CIRÍACO, Douglas. "Aprenda a utilizar o Google Docs”. 2008 Disponível em: $<$ http://www.tecmundo.com.br/692-aprenda-a-utilizar-o-google-docs.htm>. Acesso em: 08 nov. 2015.

CIRIBELLI, Marilda Corrêa. "Como elaborar uma Dissertação de Mestrado através de pesquisa científica”. Rio de Janeiro: 7Letras, 2003.

FAZENDA, Ivani Catarina Arantes. "Interdisciplinaridade: um projeto em parceria". Loyola $5^{\text {a }}$ ed. São Paulo. 2002

GIL, Antonio Carlos. "Metodologias e técnicas de pesquisa social". $6^{\text {a }}$ ed. São Paulo: Atlas, 2009.

LIBÂNEO, José Carlos. “Didática”. 2ª ed. São Paulo: Cortez, 2013.

PIMENTEL, Mariano; FUKS, Hugo (Org.). "Sistemas Colaborativos". Série Campus / SBC - Sociedade Brasileira de Computação. Elsevier Editora, 2012.

Portaria $\quad \mathrm{n}^{\mathrm{o}} \quad$ 114/2018-SEEC/GS. Disponível em $<$ http://www.diariooficial.rn.gov.br/dei/dorn3/docview.aspx?id_jor=00000001\&data=201801 24\&id_doc $=598268>$. Acesso em: 09 jun. 2018.

SALES, Selma Bessa; CRUZ, Alba Liarth da. "Uma experiência de formação de professores para o uso das ferramentas digitais e criação de redes de aprendência." In: Congresso Brasileiro de Informática da Educação, 26 a 30 nov. 2012. Anais (online) do XVIII WIE - 
VII Congresso Brasileiro de Informática na Educação (CBIE 2018)

Anais do XXIV Workshop de Informática na Escola (WIE 2018)

Workshop de Informática na Educação. p. 1894-1904. Rio de Janeiro: WIE, 2012. Disponível em: <http://www.br-ie.org/pub/index.php/wie/article/view/2128/1894>. Acesso em: 30 jun. 2018. 